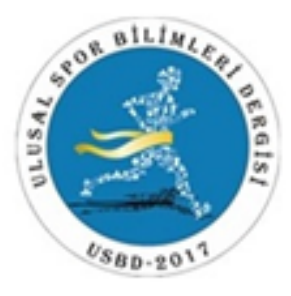

\title{
Spor Alanında Öğrenim Gören Üniversite Öğrencilerinin Çeşitli Değişkenler Açısından Umut Düzeylerinin İncelenmesi*
}

\author{
Ali Dursun AYDIN ${ }^{1}$, Hikmet TURKAY ${ }^{2 \dagger}$, Çağrı ARI ${ }^{3}$, Esengül GÜNGÖZ ${ }^{4}$, Hülya AYDIN ${ }^{5}$ \\ ${ }^{1}$ Kafkas Üniversitesi Sarıkamış Beden Eğitimi ve Spor Yüksekokulu. https://orcid.org/0000-0001-7386-8490 \\ ${ }^{2}$ Kafkas Üniversitesi Sarıkamış Beden Eğitimi ve Spor Yüksekokulu. https://orcid.org/0000-0002-7851-2757 \\ ${ }^{3}$ Gazi Üniversitesi Sağlık Bilimleri Enstitüsü Beden Eğitimi ve Spor ABD. https://orcid.org/0000-0001-9910-7518 \\ ${ }^{4}$ Kafkas Üniversitesi Sarıkamış Meslek Yüksekokulu. https://orcid.org/0000-0002-1257-0938 \\ ${ }^{5}$ Kafkas Üniversitesi Sağlık Bilimleri Enstitüsü Beden Eğitimi ve Spor ABD. https://orcid.org/0000-0003-1943-8398
}

\section{Orijinal Makale}

Gönderi Tarihi: 26.09.2019
Kabul Tarihi: 19.12.2019
DOI: $10.30769 /$ usbd.624924

Online Yayın Tarihi: 31.12.2019

Öz

Bu çalışmanın amacı, üniversitelerin spor bilimleri alanında öğrenim gören öğrencilerin umut düzeylerinin çeşitli sosyodemografik özellikler açısından incelenerek, farklılıkların ortaya çıkarılmasıdır. Araştırmanın çalışma grubunu, Gazi Üniversitesi Spor Bilimleri Fakültesi ile Kafkas Üniversitesi Sarıkamış Beden Eğitimi ve Spor Yüksekokulu' nda öğrenim gören öğrenciler (97 kız ve 102 erkek) oluşturmaktadır. Veri toplama aracı olarak, Synder ve arkadaşları (1991) tarafından geliştirilen ve Akman ve Korkut (1993) tarafından Türkçe' ye uyarlanan Umut Ölçeği kullanılmıştır. Verilerin analizinde SPSS 22 paket programından yararlanılmıştır. Araştırmada sonuç olarak; beden eğitimi öğretmenliği, spor yöneticiliği ve antrenörlük eğitimi bölümlerinde okuyan öğrencilerin cinsiyet değişkenine göre umut düzeylerinde bir farklılık bulunamazken, bölüm, sınıf ve aile gelir durumlarına göre aralarında anlamlı farklılıklar olduğu tespit edilmiştir.

Anahtar kelimeler: Beden Eğitimi, Spor, Umut.

\section{Investigation of Hope Levels of University Students in Sport Area in Terms of Various Variants}

\begin{abstract}
The aim of this study is to investigate the hopes of students studying in sports sciences in terms of various sociodemographic characteristics and to reveal the differences. The study group consisted of students (97 girls and 102 boys) from Gazi University Faculty of Sport Sciences and Kafkas University Sarıkamıs School of Physical Education and Sports. As data collection tool, Hope Scale developed by Synder et al., (1991) and adapted to Turkish by Akman and Korkut (1993) was used. SPSS 22 package program was used for data analysis. As a result of the research; while there was no difference in the level of hope of the students studying in physical education teacher, sports management and coaching education departments, there were significant differences between them according to department, class and family income.

Keywords: Physical education, Sport, Hope.
\end{abstract}

\footnotetext{
* Bu çalışma, 28. Uluslararası Eğitim Bilimleri Kongresinde Sözel Bildiri (Özet) olarak sunulmuştur.
}

†Sorumlu Yazar: Hikmet TURKAY, hikmet.turkay1@gazi.edu.tr. 


\section{GíRiş}

Umut konusu son zamanlarda birçok bilim dalı tarafından, geniş bir bakış açısıyla işlenen bir konu olarak dikkat çekmektedir. Özellikle sosyal bilimciler, çeşitli şekillerde umut konusunu araştırmış ve gelecek amaçlar hakkındaki duygu ve beklentiler olarak, kavramı açıklamaya çalı̧̧ıı̧̧ardır.

Yaşam içerisinde bulunan ve insanın varoluşunu tehdit eden, içsel ya da dışsal engeller karşısında "ruhun çabası (the anchor of the soul)" olarak, bireyin umutsuzca sürüklenmesini engelleyen bir duygu olan umut kavramı; İngilizce'de "hope", Almanca'da "hoffen", Fransizca'da "espérer" gibi sözcüklerle ifade edilmektedir (Karaca ve Kandemir, 2016). Umut, gelecekle ilgili amaç ve hedeflere ulaşma yeteneği hakkında, olumlu zihinsel bir durum olarak düşünülmektedir. Bir başka açıdan umut, zorluklara karşı bireylerin inançlarını devam ettirebilmelerini sağlayan bir duygu olarak görülmektedir (Seçer ve Yazıc1, 2018). Synder'a (2002) göre umut, başarı önünde engel oluşturabilecek faktörlerin yönetimini de kapsayan uzun vadeli hedeflere yönelik eylem başlatmaya ve sürdürmeye yardımcı olan bir etkendir.

Umut, hedefle ilgili yeteneklerin subjektif değerlendirmelerini de etkilemektedir (Snyder, 2000). Umudu yüksek bireyler, amaçlarını devam ettirmede başarılı olma eğilimindedirler ve sonuç olarak daha olumlu duygular yaşarlar. Umudu düşük bireyler ise, hedeflere ulaşmadaki engelleri aşmada daha fazla zorluk çekmeye meyillidir ve bu nedenle daha olumsuz duygular deneyimleme eğilimindedirler (Marques, Lopez ve Pais-Ribeiro, 2011).

Umut, fiziksel ve zihinsel sağlıktan akademik ve atletik başarıya kadar birçok önemli sonucu öngörmektedir (Snyder, 2002). Araştırmalar, bireylerin umutlu düşünce yapılarının algılanan yetkinlik ve benlik saygısı ile pozitif ilişkili olduğunu ve depresyon belirtileri ile de, negatif olarak ilişkili olduğunu göstermiştir (Marques, Pais-Ribeiro ve Lopez, 2011). Bazı araştırmalarda umut; akademik başarı ve psikolojik uyumla pozitif ilişkisinin yanı sıra fiziksel hastalıkların teşhis, önleme ve tedavisinde de önemli rol oynamaktadır (Kemer ve Atik, 2005). Curry ve ark., (1997), üniversite öğrencilerinin umut düzeylerinin, akademik ve spor performansları dışında psikolojik ve fiziksel durumlarını da olumlu yönde etkilediğini araştırmalarında ifade etmişlerdir.

Ülkemizde üniversiteli gençlerin umut düzeyinin araştırıldığı az sayıdaki çalışmalarda görülen, gençlerin ülkemizde yaşanan sorunlar karşısında karamsar olduğudur (Çelikel ve Erkorkmaz, 2008). Oysaki gençler, içinde bulundukları toplumların umutları, coşkuları ve gelecekleridirler (Çeviker, Mumcu, Şekeroğlu ve Bayrak, 2018). Üniversiteli gençlerin umut düzeylerini olumsuz yönde etkileyen sorunların başında, sosyal ve ekonomik sorunlar ve gelecek kaygısı gibi etkenler gelmektedir. Bu etkenlerin dışında aile ve yaşanan çevre de büyük önem teşkil etmektedir. Bu kapsam doğrultusunda çalışmada, Spor Bilimleri alanında öğrenim gören öğrencilerin umut düzeylerinin çeşitli sosyodemografik değişkenler çerçevesinde araştırılması amaç edinilmiştir. 


\section{YÖNTEM}

\section{Araştırmanın Modeli}

Bu araştırmada, Spor Bilimleri alanında öğrenim gören öğrencilerin umut düzeylerinin çeşitli sosyodemografik değişkenler kapsamında araştırılması amaçlanmıştır. Bundan dolayı araştırma kapsamında; "geçmişte ya da halen varolan bir durumu varolduğu şekliyle betimlemeyi amaçlayan ve araştırmaya konu olan olay, birey ya da nesnenin, kendi koşulları içinde ve olduğu gibi tanımlanmaya çalışıldığı” tarama modeli kullanılmıştır (Karasar, 2014).

\section{Çalışma Grubu}

Araştırma, 2018-2019 eğitim öğretim y1lında Kafkas Üniversitesi ve Gazi Üniversitesinin Spor Bilimleri alanında öğrenim gören öğrencileri üzerinde yürütülmüştür. Araştırmanın çalışma grubunu, uygulamanın yapıldığ gün okulda bulunan ve araştırmaya gönüllü katılım sağlayan Antrenörlük Eğitimi, Beden Eğitimi Öğretmenliği ve Spor Yöneticiliği bölümlerinde öğrenim gören, 102 erkek ve 97 kadın öğrenci oluşturmaktadır. Araştırmaya katılan 113 öğrenci Kafkas Üniversitesinde öğrenim görürken, 86 öğrenci Gazi Üniversitesinde öğrenim görmektedir.

\section{Veri Toplama Aracı}

$\mathrm{Bu}$ araştırmada; uzman görüşü de alınarak araştırmacılar tarafindan hazırlanan ve sosyodemografik değişkenleri ölçen Kişisel Bilgi Formu ve öğrencilerin umut düzeylerini ölçmek için; Snyder ve ark., (1991) tarafından geliştirilen ve Akman ve Korkut (1993) tarafından Türkçe uyarlaması yapılan 12 maddeden oluşan Umut Ölçeği kullanılmıştır.

Umut ölçeğinin, alt boyutlarına ait (amaca götüren yollar, planlama ve amaca ilişkin motivasyon) eşit sayıda (dörder madde) ifadeler yer almaktadır. Umut ölçeğinin amaca götüren yollar, planlama ve amaca ilişkin motivasyon boyutlarını yansıtan maddelerde olumlu, doldurucu maddelerde ise olumsuz ifadeler yer almaktadır (Akman ve Korkut, 1993).

\section{Verilerin Analizi}

Çalışma kapsamında elde edilen veriler, SPSS 22 istatistik programı ile analiz edilmiştir. Verilerin analizine geçmeden önce, verilerin normallik varsayımını sağlayıp sağlamadı̆̆ Basıklık (Kurtosis) ve Çarpıklık (Skewness) değerleri incelenerek belirlenmiştir. Umut düzeyine ilişkin veri setinin, Basıklık katsayısı -,595, Çarpıklık katsayısı -,227 olarak bulunmuştur. Basıklık ve Çarpıklık katsayıları incelendiğinde, Tabachnick ve Fidel (2015)'in belirttiği sınırlar içerisinde $(-1.5$ ile +1.5$)$ yer alan veri setinin normal bir dağılıma sahip olduğu tespit edilmiştir. $\mathrm{Bu}$ yüzden çalışma kapsamında parametrik testlerden, ikili karşılaştırmalar için Bağımsız Gruplar için T-Testi, ikiden fazla grubun bulunduğu karşılaştırmalarda ise Tek Yönlü Varyans Analizi (One-Way Anova) kullanılmıştır. Tek yönlü varyans analizi sonuçlarının anlamlı çıkması durumunda, farklılığın hangi gruplar arasında oluştuğunu belirlemek amaciyla Tukey HSD çoklu karşılaştırma testi uygulanmıştır. Araştırma grubunu oluşturan öğrencilerin kişisel özelliklerinin ortaya çıkarılmasında, frekans (f), yüzde (\%), ortalama $(\overline{\mathrm{X}})$ ve standart sapma (ss) gibi betimsel istatistik yöntemlerinden faydalanılmıştır. 


\section{BULGULAR}

Araştırmanın bu bölümünde istatistiksel analizler neticesinde elde edilen verilere ilişkin bulgu ve yorumlara yer verilmiştir.

Tablo 1. Öğrencilerin umut ölçeği puanlarının cinsiyet değişkenine göre farklılı̆̆ı için t- testi sonuçları

\begin{tabular}{ccccccc}
\hline Cinsiyet & $\mathbf{n}$ & $\overline{\boldsymbol{x}}$ & $\mathbf{s}$ & sd & t & p \\
\cline { 1 - 3 } Kadın & 97 & 24,51 & 4,42 & 197 & 1,466 & .144 \\
\cline { 1 - 3 } Erkek & 102 & 23,56 & 4,81 & & & \\
\hline
\end{tabular}

Analiz sonuçlarına göre, öğrencilerin umut düzeyleri cinsiyet değişkenine göre anlamlı bir farkl111k göstermemektedir $\left[\mathrm{t}_{(197)}=1.466 ; \mathrm{p}>.05\right]$.

Tablo 2. Öğrencilerin umut düzeylerinin bölüm değişkenine göre farklılaşmasına ilişkin tek yönlü varyans analizi (Anova) sonuçları

\begin{tabular}{|c|c|c|c|c|c|c|}
\hline Bölüm & $\mathbf{N}$ & $\overline{\bar{x}}$ & $\mathbf{s}$ & $\mathbf{F}$ & $\mathbf{p}$ & Fark \\
\hline Beden Eğitimi Öğretmenliği ${ }^{1}$ & 40 & 25,97 & 4,29 & & & \\
\hline Spor Yöneticiliği ${ }^{2}$ & 109 & 22,76 & 4,26 & 10,513 &, 000 & $1-2$ \\
\hline Antrenörlük ${ }^{3}$ & 50 & 25,24 & 4,60 & & & $2-3$ \\
\hline Toplam & 199 & 24,03 & 4,56 & & & \\
\hline
\end{tabular}

Öğrencilerin umut düzeylerinin, okudukları bölümlere göre farklılaşıp farklılaşmadığı tek yönlü ANOVA testi ile analiz edilmiş ve istatistiksel açıdan anlamlı bir farklılık bulunmuştur $\left[\mathrm{F}_{(2-196)}=10,513 ; \mathrm{p}<.05\right]$. Anlamlı farklılıkların hangi gruplar arasında olduğunu belirlemek amacıyla Tukey HDS çoklu karşılaştırma testi yapılmıştır. Çoklu karşılaştırma testi sonuçlarına göre, gruplar arası farklılığın, "Beden Eğitimi Öğretmenliği” ve "Spor Yöneticiliği” grupları arasında "Beden Eğitimi Öğretmenliği” grubu lehine, "Spor Yöneticiliği” ve "Antrenörlük Eğitimi” grupları arasında ise "Antrenörlük Eğitimi” grubu lehine gerçekleştiği belirlenmiştir.

Tablo 3. Öğrencilerin umut düzeylerinin sınıf değişkenine göre farklılaşmasına ilişkin tek yönlü varyans analizi (Anova) sonuçları

\begin{tabular}{|c|c|c|c|c|c|c|}
\hline Bölüm & $\mathbf{N}$ & $\bar{x}$ & $\mathbf{s}$ & $\mathbf{F}$ & p & Fark \\
\hline 1. Sinif ${ }^{1}$ & 25 & 23,92 & 5,21 & \multirow{5}{*}{2,947} & \multirow{5}{*}{,034 } & \multirow{5}{*}{$3-4$} \\
\hline 2.Sinif ${ }^{2}$ & 33 & 24,36 & 5,14 & & & \\
\hline 3. Sinif ${ }^{3}$ & 61 & 25,24 & 4,29 & & & \\
\hline 4. Sinif $f^{4}$ & 80 & 23,00 & 4,11 & & & \\
\hline Toplam & 199 & 24,03 & 4,56 & & & \\
\hline
\end{tabular}

Öğrencilerin umut düzeylerinin, okudukları sınıflara göre farklılaşıp farklılaşmadığı tek yönlü ANOVA testi ile analiz edilmiş ve istatistiksel açıdan anlamlı bir farklılık bulunmuştur $\left[\mathrm{F}_{(3-}\right.$ $195)=2,947 ; \mathrm{p}<.05]$. Anlamlı farklılıkların hangi gruplar arasında olduğunu belirlemek 
amacıyla Tukey HDS çoklu karşılaştırma testi yapılmıştır. Çoklu karşılaştırma testi sonuçlarına göre, gruplar arası farklılığın, "3. Sınıf” ve “4. Sınıf” grupları arasında “3. Sınıf” grubu lehine gerçekleştiği belirlenmiştir.

Tablo 4. Öğrencilerin umut düzeylerinin aile gelir değişkenine göre farklılaşmasına ilişkin tek yönlü varyans analizi (Anova) sonuçları

\begin{tabular}{|c|c|c|c|c|c|c|}
\hline Aile gelir & $\mathbf{N}$ & $\overline{\boldsymbol{x}}$ & $\mathbf{s}$ & $\mathbf{F}$ & $\mathbf{p}$ & Fark \\
\hline Gelir giderden $\mathrm{az}^{1}$ & 61 & 22,62 & 4,72 & & & \\
\hline Gelir gidere denk ${ }^{2}$ & 108 & 24,68 & 4,21 & 4,332 & ,014 & $1-2$ \\
\hline Gelir giderden fazla ${ }^{3}$ & 30 & 24,53 & 4,93 & & & \\
\hline Toplam & 199 & 24,03 & 4,56 & & & \\
\hline
\end{tabular}

Öğrencilerin umut düzeylerinin, algılanan aile gelir düzeyine göre farklılaşıp farklılaşmadığ tek yönlü ANOVA testi ile analiz edilmiş ve istatistiksel açıdan anlamlı bir farklılık bulunmuştur $\left[\mathrm{F}_{(2-196)}=4,332 ; \mathrm{p}<.05\right]$. Anlamlı farklılıkların hangi gruplar arasında olduğunu belirlemek amacıyla Tukey HDS çoklu karşılaştırma testi yapılmıştır. Çoklu karşılaştırma testi sonuçlarına göre, gruplar arası farklılı̆̆ın, "Gelir giderden az" ve "Gelir gidere denk" grupları arasında “Gelir gidere denk” grubu lehine gerçekleştiği belirlenmiştir.

\section{TARTIŞMA VE SONUÇ}

Araştırmanın temel amacı, spor bilimleri alanında öğrenim gören öğrencilerin cinsiyet, bölüm, sınıf ve aile gelir düzeyleri değişkenlerine göre farklılık gösterip göstermediğini araştırmaktır. Çünkü gençliğin sahip olduğu en önemli özelliklerden birinin umut olduğu açıktır.

Araştırmamızda belirtilen spor bilimleri alanında öğrenim gören öğrencilerin umut düzeylerinin cinsiyete göre farklılığının bulunup bulunmadığının belirlenmesi amacıyla yapılan istatistiki işlemde cinsiyete göre öğrencilerin umut düzeylerinde anlamlı düzeyde bir farklılığının bulunmadığı tespit edilmiştir. Bu sonuç Snyder ve ark., (1991) kız ve erkek öğrencilerin umut düzeyleri açısından anlamlı bir farklılık göstermedikleri sonucunu desteklemektedir. Toprak (2014) çalışmasında da, çalışma bulgularımıza paralel olarak cinsiyet değişkenine göre anlamlı farklılıklar olmadığı görülmüştür. Yine Küsgülü’nün (2014), üniversite öğrencilerinde mutluluk, umut ve narsisizm düzeylerini incelediği araştırma sonuçlarına göre üniversite öğrencilerinin cinsiyet değişkenine göre umut düzeylerinde anlamlı bir farklılaşma görülmemiştir.

Öğrencilerin umut düzeylerinin sınıf değişkenlerine göre farklılığında, üçüncü sınıftaki öğrencilerin umut düzeylerinin daha yüksek olduğu saptanmıştır. Konuyla ilgili Davidson ve ark., (2012) yaptıkları araştırmada, çalışma bulgularımızın aksine öğrencilerin umut düzeylerinin öğrenim gördükleri sınıflara göre farklılaşmadığı görülmektedir. 
Öğrencilerin umut düzeylerinin, algılanan aile gelir düzeyine göre farklılaşıp farklılaşmadığ analiz edilmiş ve istatistiksel açıdan anlamlı bir farklılık bulunmuştur. Sosyoekonomik düzey ve umudu araştıran diğer alan yazıları incelendiğinde öğrencilerinin umut düzeylerinin aile gelir düzeyi açısından farklılaşıp farklılaşmadığını araştıran az sayıda araştırmaya rastlanmıştır. Özmen ve arkadaşlarının (2008) yaptığı araştırmada, çalışma bulgularımıza paralel olarak sosyoekonomik düzeyi daha düşük olan ailelerde yaşayan gençlerin daha umutsuz oldukları görülmüştür. Bu doğrultuda, ekonomik refah seviyelerinin bireylerin umut düzeyleri üzerinde etkili olduğu söylenebilir.

Umut, öğrencilerin olumsuz durumlara müdahale performanslarını kolaylaştırmaya katkıda bulunmakta ve refah düzeylerini arttırmaktadır. Snyder ve arkadaşları (2002) umutlu düşünceyi teşvik etmenin, öğrencilerin yaşamlarının tüm alanlarındaki hedeflerini iyileştirme potansiyeline sahip olduğunu vurgulamaktadırlar. Bu sonuçlar, genel psikoloji alanındaki araştırmaları (Snyder ve ark., 1999; Snyder ve ark., 2002) ve spor psikolojisi literatürünü (Curry ve ark., 1997; Curry ve Maniar, 2003) destekleyen kanitlar sunmaktadır.

Ek olarak, gelecek çalışmalarda sosyal ilişkiler hakkında bir farkındalık ve öğrenciler arasında bağlantı ve desteğin, akran rehberliği ve grup projeleriyle açıkça teşvik edilmelidir. Benzer şekilde, gelecekte yapılacak araştırmalarda, burada kullanılan bir hedef belirleyici umut ölçüsünün aksine, daha genel umut ölçüsü kullanılabilir.

\section{KAYNAKLAR}

Akman, Y., \& Korkut, F. (1993). Umut ölçeği üzerine bir çalışma. Hacettepe Üniversitesi Eğitim Fakültesi Dergisi, 9, 193 - 202.

Curry, L., \& Maniar, S. (2003). Academic course combining psychological skills training and life skills education for university students and student-athletes. Journal of Applied Sport Psychology, 15(3), 270-277.

Curry, L. A., Snyder, C. R., Cook, D. L., Ruby, B. C., \& Rehm, M. (1997). Role of hope in academic and sport achievement. Journal of personality and social psychology, 73(6), 1257-1267.

Çelikel, F., \& Erkorkmaz, U. (2008). Üniversite öğrencilerinde depresif belirtiler ve umutsuzluk düzeyleri ile ilişkili etmenler. Nöropsikiatri Arşivi, 45(4), 122-129.

Çeviker, A., Mumcu, H. E., Şekeroğlu, M. Ö., \& Bayrak, M. (2018). UNICEF’e göre Türkiye'de dezavantajlı kabul edilen grupların sportif etkinliklerle sosyal uyumun sağlanması. Siirt Üniversitesi Sosyal Bilimler Enstitüsü Dergisi, 6(12), 221-238.

Davidson, O. B., Feldman, D. B., \& Margalit, M. (2012). A focused intervention for 1st-year college students: Promoting hope, sense of coherence, and self-efficacy. The Journal of Psychology, 146(3), 333-352. 
Karaca, F., \& Kandemir, F. (2016). Karaca-Kandemir Umut Ölçeği (KKUÖ). Recep Tayyip Erdoğan Üniversitesi İlahiyat Fakültesi Dergisi, 5(9), 7-34.

Karasar, N. (2014). Bilimsel Araştırma Yöntemi. 26. Basım. Ankara: Nobel Akademik Yayıncilik.

Kemer, G., \& Gökhan, A. (2005). Kırsal ve il merkezinde yaşayan lise öğrencilerinin umut düzeylerinin aileden algılanan sosyal destek düzeyine göre karşılaştırılması. Marmara Üniversitesi Atatürk Ĕ̆itim Fakültesi Eğitim Bilimleri Dergisi, 21(21), 161-168.

Küsgülü, Ü. (2014). Üniversite öğrencilerinin mutluluk, umut ve narsisizm düzeylerinin incelenmesi. Yüksek Lisans Tezi. Gaziosmanpaşa Üniversitesi Ĕ̈itim Bilimleri Enstitüsü, Tokat.

Marques, S. C., Lopez, S. J., \& Pais-Ribeiro, J. L. (2011). "Building hope for the future": A program to foster strengths in middle-school students. Journal of Happiness Studies, 12(1), 139-152.

Marques, S. C., Pais-Ribeiro, J. L., \& Lopez, S. J. (2011). The role of positive psychology constructs in predicting mental health and academic achievement in children and adolescents: A two-year longitudinal study. Journal of Happiness Studies, 12(6), 1049-1062.

Özmen, D., Dündar, P. E., Çetinkaya, A. Ç., Taşkın, O., \& Özmen, E. (2008). Lise ögrencilerinde umutsuzluk ve umutsuzluk düzeyini etkileyen etkenler. Anadolu Psikiyatri Dergisi, 9(1), 8-15.

Seçer, B., \& Yazıcı, M.O. (2018). Üniversite öğrencilerinde iş umudu ve tükenmişlik ilişkisi. Çalışma İlişkileri Dergisi, 9(2), 48-60.

Snyder, C. R. (2002). Hope theory: Rainbows in the mind. Psychological inquiry, 13(4), 249275.

Snyder, C. R. (2000). The past and possible futures of hope. Journal of Social and Clinical Psychology, 19(1), 11-28.

Snyder, C. R. (1999). Hope, goal-blocking thoughts, and test-related anxieties. Psychological reports, 84(1), 206-208.

Snyder, C. R., \& Forsyth, D. R. (1991). Handbook of social and clinical psychology: The health perspective. Newyork: Pergamon Press.

Snyder, C. R., Harris, C., Anderson, J. R., Holleran, S. A., Irving, L. M., Sigmon, S. T., \& Harney, P. (1991). The will and the ways: development and validation of an individual-differences measure of hope. Journal of personality and social psychology, 60(4), 570-585. 
Tabachnick, B. G. \& Fidell, L. S. (2015). Çok değişkenli istatistiklerin kullanımı. (Çev: Baloğlu, M.), 6. Baskı. Ankara: Nobel Akademik Yayıncılık.

Toprak, H. (2014). Ergenlerde mutluluk ve yaşam doyumunun yordayıcısı olarak psikolojik sağlamlılık ve psikolojik ihtiyaç doyumu. Yüksek Lisans Tezi, Sakarya Üniversitesi Eğitim Bilimleri Enstitüsü. 